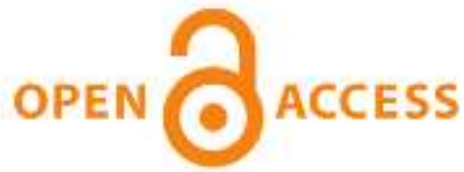

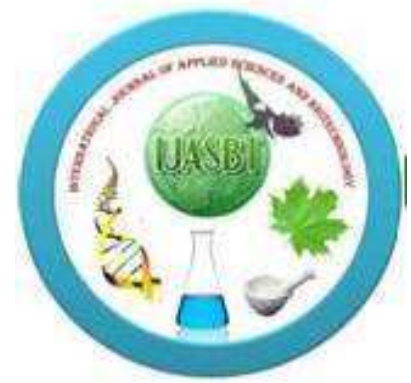 \\ International Journal of Applied Sciences and Biotechnology
}

\section{A Rapid Publishing Journal}

\section{ISSN 2091-2609}

\section{Indexing and Abstracting}

CrossRef, Google Scholar, Global Impact Factor, Genamics, Index Copernicus, Directory of Open Access Journals, WorldCat, Electronic Journals Library (EZB), Universitätsbibliothek Leipzig, Hamburg University, UTS (University of Technology, Sydney): Library, International Society of Universal Research in Sciences (EyeSource), Journal Seeker, WZB, Socolar, BioRes, Indian Science, Jadoun Science, JourInformatics, Journal Directory, JournalTOCs, Academic Journals Database, Journal Quality Evaluation Report, PDOAJ, Science Central, Journal Impact Factor, NewJour, Open Science Directory, Directory of Research Journals Indexing, Open Access Library, International Impact Factor Services, SciSeek, Cabell's Directories, Scientific Indexing Services, CiteFactor, UniSA Library, InfoBase Index, Infomine, Getinfo, Open Academic Journals Index, HINARI, etc.

\section{CODEN (Chemical Abstract Services, USA): IJASKD}

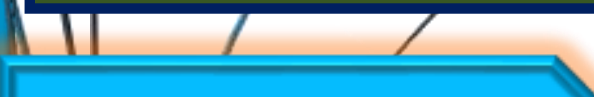

Vol-3(2) June, 2015

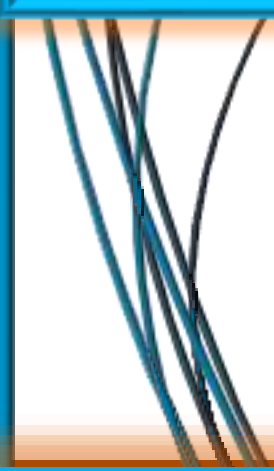

Available online at:

http://www.ijasbt.org

\&

http://www.nepjol.info/index.php/IJASBT/index

Impact factor*: $\mathbf{1 . 4 2 2}$

Scientific Journal Impact factor $\#$ : 3.419

SEM-Biotech

Publishing 


\title{
THE CAPACITY OF LIGNIN TO ENHANCE THE PHTHORIMAEA OPERCULLELA GRANULOVIRUS (PHOPGV) STABILITY IN LABORATORY CONDITION
}

\author{
Shiva Shankar Bhattarai ${ }^{1}$, Sunil Aryal ${ }^{2}$ and Resham Bahadur Thapa ${ }^{3}$ \\ ${ }^{1 *}$ Department of Horticulture and Plant Protection, Tribhuvan University, Institute of Agriculture and Animal Sciences, Paklihawa Campus, Nepal \\ ${ }^{2}$ Entomology Division, Nepal Agriculture Research Council, Khumaltar, Nepal \\ ${ }^{3}$ Department of Entomology, Tribhuvan University, Institute of Agriculture and Animal Sciences, Kirtipur,Nepal
}

*Corresponding author email: cvabhattarai@gmail.com

\begin{abstract}
The lab persistence of Phthorimaea opercullela granulovirus (PhopGV) with and without lignin for egg bioassay with different five virus concentrations (lab experiment- 60,10,1.67, 0.28 and 0.046 LE/1 20- 0.015432 LE/l ) to determine the inactivation curve under artificial UVlight, assess the effect and verify the protective capacity of lignin with PhopGV for virus preparations suspensions of raw PhopGV alone and mixed with lignin (1\%) used as UV protectants was conducted in simply completely randomised design in the laboratory condition. The LC50 value for $P$ hop $\mathrm{GV}$ in lab condition was $1 \times 10^{-3} \mathrm{LE} / \mathrm{l}$ with the slope of the probit regression line 0.51 . Similarly, half inactivation speed with lignin was 4.58 days compared to 0.559 days without lignin in lab condition. Inactivation speed was decreased by $87.8 \%$ in case of lignin applied in lab condition. So, the suppression of PTM with virus combined with lignin gave cost effective measures through the use of low dosages. In lab experiment, the control mortality of $19.6 \%$ was probable for all the controls of lignin present and absent. This revealed that there was no effect of lignin alone on target insects' survival.
\end{abstract}

Key words: Raw PhopGV; lab persistence; lignin; stability

\section{Introduction}

The potato tuber moth (PTM), Phthorimaea operculella Zeller (Lepidoptera: Gelechiidae) is the most important insect pest of potato in Nepal causing sustainable yield loss. The pest was reported for the first time in 1965 in the Kathmandu valley during the survey conducted by Entomology Section and was also reported for the next year (Entomology Section, 1965/66; 1966/67). Its infestation starts right from the field during the plant growth. Tuber yield loss of potato production ranged from $45.2 \pm 3.2$ to $78.9 \pm 10 \%$ in an unprotected potato crop as reported by Joshi (1989). Predominant means of control are through the use of broad spectrum chemical insecticides. Due to misuse of pesticides, many harmful effects have been observed on human beings and the environment (Thapa, 2003). One prime candidate of microbial bio-control agents is naturally occurring granulovirus, Phthorimaea operculella infecting Granulovirus (PhopGV, Baculoviridae) infecting potato tuber moth, which is effective in controlling PTM and can play significant role in integrated management of this pest in stored tubers and in field crops (Lacey and Arthurs, 2009; Lacey et al., 2009). However, its use in the field is limited by its rapid inactivation due to Ultraviolet (UV) radiation (Griego et al., 1985; Davidson et al., 1969). Lignin is promising UV protectants, due to its ability to absorb UV wavelengths of light thus reducing virus degradation and relatively high abundance of this woody plant polymer (Arthurs et al., 2008).

\section{Methodology}

\begin{abstract}
Sources of PhopGV, potato tuber moth and potato
Potato tuber moth neonates and PhopGV were obtained from the colony maintained at NARC Entomology Division laboratory by rearing them (Aryal, 2011). The potato was bought directly from the farmer's field assuring it without treatment of any chemicals. The potato variety used was Kufri Sindhuri which was of late variety that matched the research duration.
\end{abstract}

\section{Laboratory uses}

Various chemicals and equipments were used during the entire research duration in the laboratory. Tween-80 was used as a surfactant for the uniform spreading of virus particles in the solution. Rectangular boxes of 0.5 liter capacity (5 cm depth, $15 \mathrm{~cm}$ in length and $10 \mathrm{~cm}$ width) were used as the rearing materials. Sodium hypochlorite was used as a disinfectant against pathogen while rearing PTM. Micropippette of 100 microliter was used for pouring virus suspension over the PTM eggs. Lignin sulphonic acid sodium salt (Himedia Laboratories, Pvt. Ltd, India) was 
used as an UV protectants. UV lamp of wavelength 280$320 \mathrm{~nm}$ was used as the sources of artificial radiation.

\section{Preparation of virus suspensions}

Sixty matured PhopGV infected larvae were crushed in a mortar and pestle and diluted in 1 liter of water, thus forming a stock solution of 60LE/liter as unpurified PhopGV suspension. Then the stock solution was further diluted six times to obtain four lower concentrations i.e., 10, 1.67, 0.28 and 0.046 LE/l. Few drops of Tween 80 was added in the solution. Here, the lignin for $1 \%$ was prepared and mixed with every concentrated solution. Control lignin was prepared by mixing $1 \%$ lignin with water only. Control only was prepared without mixing anything in water only. Again the few drops of Tween 80 were added in the solution.

These solutions without mixing lignin were also prepared. UV lamp of wavelength 290-320 nm was used as the source of artificial radiation. The radiation was emitted by UV lamp keeping different solution at certain distance of 1 meter for about 5 minute. Regular inspection of UV lamp was done so that the lamp didn't get off automatically. All the five concentrations of solutions, control solutions and control lignin were exposed to different time i.e., $0,2,4,8$, 16,32 and 64 mins.

\section{Application of virus suspension}

The viral suspensions of different concentration were poured over PTM eggs using the micropipette that holds 100 micro liter of solution. When the eggs hatched they consumed the virus and were transferred to potato tubers and survival assessed after 14 days and again after 20 days. Also the solutions exposed to UV lamp at different time were taken out from the exposure and were treated to PTM eggs.

\section{Bioassay process}

A rectangular plastic box of 0.5 litre capacity $(5 \mathrm{~cm}$ depth, $15 \mathrm{~cm}$ in length and $10 \mathrm{~cm}$ width) had been used in bioassay for test insect incubated over potato tuber. For ventilation, rectangular hole $\left(3 \times 2 \mathrm{~cm}^{2}\right)$ was cut in the centre of the lid of each boxes and sealed with polyester mesh. The solution treated eggs were kept over the filter paper so that the extra solutions were dried over to the paper. The treated eggs were then kept inside the plastic petridishes which are covered with a lid and tied with a parafilm wax over it so that no larvae escape out of it. After hatching of the eggs, the emerging larvae fed upon the egg chorion that took up the virus particles attached to the eggshell. This uptake might cause infection in the larvae. The inactivation of PhopGV was found out with respect to time among the same solution.

\section{Data collection}

The proportion of infected forth instar larvae were counted and younger larvae were reared on the tubers to confirm the infection status. The infected larvae were recognized as fully developed forth instar larvae with creamy white color and sluggish movement. Mortality was recorded as failure to pupate after an overall incubation period of 14 days. Under control mortality and control lignin mortality, the number of absent larvae was counted as natural mortality.

The infected larvae were counted after 14 days of larvae inoculation. The larva showing typical whitish, full bodied and sluggish movement were identified as viral infected larvae. These were unable to pupate. The proportion of larvae unable to pupate was counted as mortality. Similarly, some larvae couldn't develop to further stage without application of viral particles. Such dead larvae were counted as control mortality or control lignin mortality.

\section{Statistical analysis}

The data from all the experiments were recorded and managed in spreadsheet. The concentration of each pathogen were log transformed at the base of 10 . The correction for natural mortality was done according to the formula by Abott (1925).

$$
\text { Adjusted mortality }(\%)=\frac{\text { observed mortality }(\%)-\operatorname{control} \text { mortality }(\%) \times 100}{100-\operatorname{control} \text { mortality }(\%)}
$$

Exponential half-life, or half-inactivation time of the virus, $t_{1 / 2}$ (Rutherford, 1907) calculated using equation:

$t 1 / 2=\log 0.5 / b$ (single exponential decay) where $b$ is the slope of the regression obtained after plotting the log activity $\left(\log R_{x}\right)$ against the time of exposure

$t 1 / 2=\ln (2) / k 1$ or $k 2$, where $\mathrm{k} 1, \mathrm{k} 2$ are the inactivation.

The $\mathrm{LC}_{50}$ value were calculated as:

$\mathrm{LC}_{50}=-\exp (\mathrm{a} / \mathrm{b})$ where $\mathrm{a}$ is the intercept and $\mathrm{b}$ is the slope of the regression of probit line.

The data followed a bisegmented inactivation curve or Hiatt model (1964),

Activity $=(1-\gamma) * \operatorname{EXP}(-(k 1+k 2) * \mathrm{t})+\gamma^{*} \operatorname{EXP}(-k 2 * \mathrm{t})$

Where ' $\mathrm{t}$ ' is the radiation time in minutes, $k 1, \mathrm{k} 2$ are the inactivation coefficients and $\gamma$ is the proportion of virus particles with increased resistance against UV.

\section{Comparing models}

The collected data were analyzed by using Hiatt modelling. In second step, the goodness of fit was estimated by comparing models on the basis of change in Akaike Information Criterion (AIC). Further statistical evidence was given by F-test and probability test. The model with higher deviance value is simple model and that with the lower deviance value is complicated model. Calculated Probability $\mathrm{P}_{\text {calc }}$ value is compared with traditional $\mathrm{P}$ value, i.e. 0.05 where simple model is significantly better if $\mathrm{P}_{\text {calc }}$ $>0.05$ (Motulsky, 2007). MS Excel was used as computer software. 


\section{Results}

\section{Lignin effect on the inactivation time of the pathogen}

Using Hiatt model (1964), Model 3 with $\triangle$ AIC -13.5 value was significantly better according to F-test and probability test. The inactivation coefficient $k l$ was same for all treatment and bioassay methods, i.e. $k 1_{\text {lignin }}=k l_{\text {without lignin }}=$ 0.538 corresponding to a half inactivation speed of 0.559 min. The other inactivation coefficient $k 2$ was different for lignin treated and non-treated virus, where $k 2_{\text {lignin }}=0$, no further inactivation, $k 2_{\text {without lignin }}=0.0657$ corresponding to the half inactivation speed of $4.58 \mathrm{~min}$. The $\mathrm{LC}_{50}$ value was $1 \times 10^{-3} \mathrm{LE} / \mathrm{ltr}$. The difference in inactivation speed of lignin treated and non-treated resulted the difference in inactivation curve (Fig. 1 and 2). Parameters of different models and comparison of models of lab experiment have been shown in Table-1 and 2.

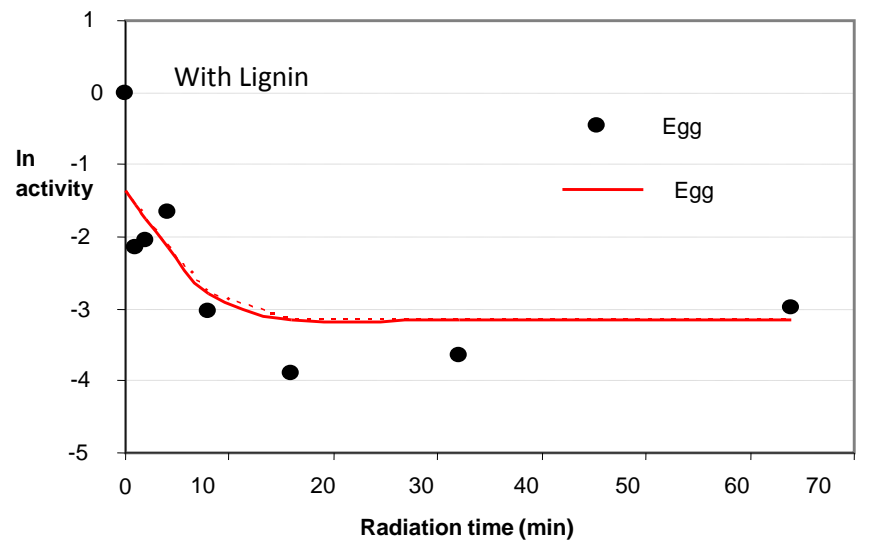

Fig. 1: Showing inactivation with lignin in egg bioassay under bisegmented inactivation curve in lab experiment.

\section{Lignin effects on the target insect}

The control lignin mortality compared to control mortality didn't show significant differences. The observed control mortality rates were compared with the expected mortality rate using chi square value and probability value. The $\mathrm{P}_{\text {calc }}$ value $>0.05$ which is the traditational $\mathrm{P}$ value (Motulsky, 2007). This proved that different control mortalities were not significant and expected control mortality $19.6 \%$ was probable for all control which is shown in the Table 3.

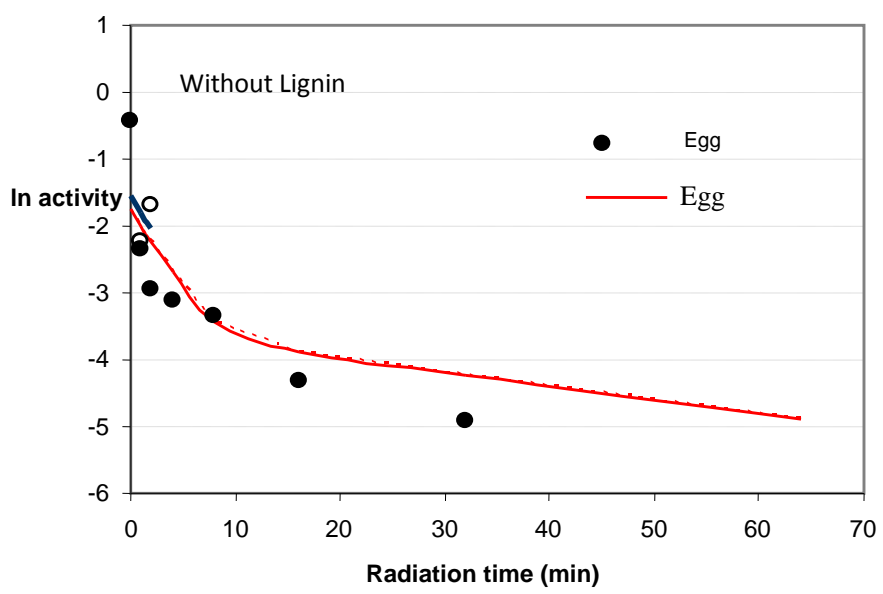

Fig. 2: Showing inactivation without lignin in egg bioassay under bisegmented inactivation curve in lab experiment.

Table 1: Showing the parameters of different models of lab experiment

\begin{tabular}{|c|c|c|c|c|c|c|c|c|c|c|}
\hline Model & Assay & UV screen & Intercept & $k 1$ & $k 2$ & $\log \gamma$ & Deviance & $\mathbf{N}$ & $\mathbf{P}$ & $\Delta \mathrm{AIC}$ \\
\hline \multirow[t]{2}{*}{1} & Egg & Lignin & -1.3582 & 0.480872 & 0 & -1.80609 & \multirow[t]{2}{*}{11.99} & \multirow[t]{2}{*}{32} & \multirow[t]{2}{*}{7} & \multirow[t]{2}{*}{-9.16} \\
\hline & Egg & without Lignin & -1.75319 & 0.517759 & 0.047405 & -1.80609 & & & & \\
\hline \multirow[t]{2}{*}{2} & Egg & Lignin & -1.43671 & 0.442235 & 0 & -1.7504 & \multirow[t]{2}{*}{12.08} & \multirow[t]{2}{*}{32} & \multirow[t]{2}{*}{6} & \multirow[t]{2}{*}{-15.08} \\
\hline & Egg & without Lignin & -1.43671 & 1.044451 & 0.06462 & -1.7504 & & & & \\
\hline \multirow[t]{2}{*}{3} & Egg & Lignin & -1.53288 & 0.538571 & 0 & -1.67081 & \multirow[t]{2}{*}{12.98} & \multirow[t]{2}{*}{32} & \multirow[t]{2}{*}{5} & \multirow[t]{2}{*}{-13.5} \\
\hline & Egg & without Lignin & -1.53288 & 0.538571 & 0.065673 & -1.67081 & & & & \\
\hline \multirow[t]{2}{*}{4} & Egg & Lignin & -1.53288 & 0.387779 & 0.008733 & -1.90529 & \multirow[t]{2}{*}{17.29} & \multirow[t]{2}{*}{32} & \multirow[t]{2}{*}{4} & \multirow[t]{2}{*}{-7.4} \\
\hline & Egg & without Lignin & -1.80675 & 0.387779 & 0.008733 & -1.90529 & & & & \\
\hline
\end{tabular}

$\mathrm{k} 1, \mathrm{k} 2$ are the inactivation coefficients, $\log \gamma$ is the proportion of virus particles with increased resistance against UV, Deviance is the sum of squares of data, $\mathrm{N}$ is the number of data points, $\mathrm{P}$ is the number of parameters, $\triangle \mathrm{AIC}=\mathrm{N} \mathrm{x} \ln (\mathrm{SS} 2 / \mathrm{SS} 1)+2 \Delta \mathrm{DF}$, where $\mathrm{N}$ is the number of parameters points, $\mathrm{SS} 2$ and $\mathrm{SS} 1$ are the sum of squares of simple and complicated models respectively, $\triangle \mathrm{DF}$ is the change in degree of freedom. 
Table 2: Comparison of models in lab experiment

\begin{tabular}{|l|l|l|l|}
\hline Comparison of models & F-ratio & P $_{\text {calc }}$ & Significantly better model \\
\hline 1 and 2 & 0.20 & 0.6561 & Model 2 \\
\hline 2 and 3 & 1.94 & 0.1755 & Model 3 \\
\hline 3 and 4 & 8.94 & 0.0058 & Model 3 \\
\hline
\end{tabular}

Table 3: Showing comparison between observed and expected control mortalities using chi square and probability test

\begin{tabular}{llllllll}
\hline Type of controls & Total larvae & Dead larva & Survivors & Observed mortality & Expected mortality & Chi square & Pcalc \\
\hline Control E & 30 & 5 & 25 & $16.7 \%$ & $19.6 \%$ & 0.1292 & $0.72(\mathrm{~ns})$ \\
Control lignin 1\% E & 35 & 8 & 27 & $22.9 \%$ & $19.6 \%$ & 0.1933 & $0.66(\mathrm{~ns})$ \\
\hline
\end{tabular}

Control E- Control from egg bioassay, ns- non-significant

\section{Discussion}

In our study of lab experiment, the common slope of 0.51 was obtained, which was more or less similar to the result obtained by Briese and Mende (1981) where the authors observed a slope of $0.565-1.028$. Aryal (2011) observed a common slope of 0.58 for the Entomology Division Laboratory isolate for all the bioassays. Our study revealed $\mathrm{LC}_{50}$ values $1 \times 10^{-3} \mathrm{LE} /$ liter for lab experiment. Aryal (2011) observed the $\mathrm{LC}_{50}$ values ranged from 10.3 to 50.6 $\mathrm{LE} / 10^{-4}$ liter of water for the Entomology Division Laboratory isolate for all the bioassays. Pandey (2009) found $\mathrm{LC}_{50}$ value ranging from $1.91 \times 10^{-4}-9.49 \times 10^{-4}$ larval equivalent per liter (LE/L). In our result, the half-life of 0.60 days was observed in the lab experiment. The study revealed that half-life of 0.73 days, and 0.53 days was calculated for the PhopGV. The inactivation speed was reduced by $87.8 \%$ in case of lignin treated compared to nonlignin treated in lab condition. Arthurs et al. (2008) observed the reduction of inactivation speed by $78 \%$ in Cydia pomonella Granulovirus by lignin treatment. Lignin didn't affect the survival of moths since the same control mortality, i.e. $19.6 \%$ was probable for all the control, i.e. either lignin treated or not treated.

\section{Acknowledgement}

The first author is thankful to International Potato Center (CIP), Peru for financial supports and Nepal Agriculture Research Council (NARC) for technical supports. It is my pleasure to express my sincere gratitude to Prof. Resham Bahadur Thapa, Ph. D, Chairman of Advisory Committee, for providing continuous guidance and valuable suggestion from the beginning of the proposal writing, during experimental period and thesis write-up. I am also grateful to the members of my Advisory committee, Mr. Yagya Prasad Giri, Senior Scientist (S4) from Nepal Agriculture Research Council (NARC), for his continuous support, encouragement and suggestion; and Dr. Marc Sporleder, CIP for his continuous support from the time of proposal writing to the analysis of the data.

\section{References}

Abbott WS (1925) A method for computing the effectiveness of an insecticide. Journal of Economic Entomology. 18:265267.

Arthurs SP, Lacey LA and De La Rosa F (2008a) Evaluation of a Granulo-virus (PoGV) and Bacillus thuringiensis sp. Kursataki for control of the Potato Tuberworm, (Lepidoptera: Gelechiidae) in Stored Tubers. Journal of Economic Entomology 101(5): 1540-1546.

Arthurs SP, Lacey LA and Behier RW (2008) Evaluation of lignins and particle films as solar protectants for the granulovirus of the codling moth, Cydia poinonella. Biocontrol Science and Technology 18: 829 -839

Arthurs SP, Lacey LA, Pruneda JN and Rondon SI (2008b) Semifield evaluation of a granulovirus and Bacillus thuringiensis ssp. Kurstaki for season-long control of the potato tuber moth, Phthorimaea operculella. Entomologia Experimentalis et Applicata 129: 276-285.

Aryal S (2011) Management of the potato tuber moth, Phthorimaea operculella Zeller, (lepidoptera: gelechiidae) using indigenous granulovirus isolate. Thesis, M. Sc. IAAS. Tribhuvan University $72 \mathrm{p}$.

Briese DT and Mende HA (1981) Differences in susceptibility to a granulosis virus between field populations of the potato tuber moth, Phthorimaea operculella (Zeller) (Lepidoptera:Gelechiidae). Bulletin of Entomological Research 71:11-18.

Davidson MM, Takla MFG, Reader JK, Butler RC, Wratten SD and Conner AJ (1969) Evaluation of field grown potato lines transgenic for a crylac9 gene conferring resistance to potato tuber moth. Journal of New Zealand Plant Protection 55:405-410.

Entomology Section (1965) Annual Report. 1965/66. Entomology Section. HMG. Agricultural Education and Research Division, Shreemahal, Nepal. 32 p.

Entomology Section (1966) Annual Report. 1965/66. Entomology Section. HMG. Agricultural Education and Research Division, Shreemahal, Nepal. 47 p. 
Finney JR (1971) Probit Analysis.Third edition. Cambridge University Press, Cambridge, UK. 333 p.

Griego VM, Martignoni ME and Claycomb AE (1985) Inactivation of nuclear polyhedrosis virus (Baculovirus subgroup A) by monochromatic UV radiation. Journal of Applied Environmental Microbiology 49(3):709-710.

Hiatt CW (1964) Kinetics of the inactivation of viruses. Bacteriological Review.28

Joshi SL (1989) Comparative life cycle of the potato tuber moth, Phthorimaea operculella (Zeller) (Lepidoptera: Gelechiidae) on potato tubers and foliages and its economic loss in yield. Journal of Entomological Society of Nepal 1: 59-69.

Lacey LA and Arthurs SP (2005) New Method for Testing Solar Sensitivity of Commercial Formulations of the
Granulovirus of Codling Moth (Cydia pomonella,Tortricidae: Lepidoptera), Journal of Invertebrate Pathology: 90:85 -90.

Motulsky HJ (2007) Prism 5 Statistics Guide. GraphPad Software. San Diego CA.

Pandey S (2009) Biological activity of different microbials and their interaction in the potato tuber moth, Phthorimaea operculella (Zeller) in laboratory. Thesis, M. Sc. IAAS. Tribhuvan University 77 p.

Thapa RB (2003) Pesticide pollution and integrated pest management. In: F. P. Neupane (ed.) Proceeding of National Seminar on Integrated Pest Management in Nepal, 25-26 September 2002. Himalayan Resources Institute, New-Baneshwor, Kathmandu, Nepal. pp. 175 197. 